\section{Obituary - In memory of Prof. Renzo Galanello}

Prof. Renzo Galanello, a worldwide expert in thalassemic syndromes, died in Cagliari after a few months of a severe illness on May 13, 2013, at the age of 65 .

He was born on $21^{\text {st }}$ of July 1948 in Parrano, a small village in Umbria, nearly $35 \mathrm{~km}$ South of Perugia. He obtained an MD degree at the University of Perugia, where, from 1973 to 1975 , he worked as assistant in the Pediatrics Clinic directed, by Prof. Antonio Cao. He obtained his Specialization in Pediatrics in 1975, and then followed his Master to Cagliari, where Prof. Cao was appointed Director of the Pediatrics Division at the Microcetimico Hospital. Prof. Galanello in 1978 took another Specialization in Puericulture, then became Director of the Division of Pediatrics Hematology in 1985. In 1998 he became Director of the Day Hospital Service for Thalassemia patients. In 2006 he was appointed Director of the second Pediatric Clinics in the same Hospital, and then Head of the Department of Biomedical and Biotechnological Sciences from 2008 to 2011. He was Full Professor of Pediatrics from 2001, and Director of the Pediatrics Specialization School from 2009 .
Prof. Galanello gave a major contribution to the field of molecular genetics and care of thalassemia syndromes, following the paths of his Master, Prof. Antonio Cao. Today much information on bibliometric indexes is available, though I have not searched for the $\mathrm{H}$ index or similar things about Renzo. He was not so enthusiastic about these tools and he hated the rigidity of bureaucracy. However, simply by looking at his curriculum, the number of papers published on journals such as Blood, American Journal of Hematology, British Journal of Hematology, etc. is considerable. I am honored to have worked with him at the end of the 1990s to the validation of a number of high performance liquid chromatography methods for the analysis of human hemoglobins. We also collaborated to the characterization of various abnormal hemoglobins, as well to the validation of some new methods for the assay of G6PD activity. I have invited him several times to the Congresses of our National Society of Clinical Biochemistry and Clinical Molecular Biology (SIBioC) where he was used to give a revealing speeches on various cases of thalassemic syndromes with his usual clarity of thought and masterly of expression. To the laboratory professionals he really opened the frontiers of the genetic consulting and preand peri-natal diagnosis.

In the past years he travelled a lot, always invited to report the most important clinical trials he was taking part in, together with the Microcitemico Hospital he was representing. Nonetheless, every summer, as a migrating bird, he would come back for a couple of weeks to his original small village of Parrano, of which he had also been Major from 1970 to 1975. Always with his intense devotion to the problems of the people and the beautiful nature surrounding the village.

To conclude this short memory, I would like to quote Renzo as a great chef, loving mostly very simple and organic food. He loved to prepare meals for his family and friends, and I think that this may be linked to his scientific excellence. A good chef, like a good researcher, does not care about recipes too much; in fact, he chooses good ingredients, blends them together in good harmony, and constantly monitors the product of his work to improve it continuously.

Prof. Galanello was married to Maria Antonietta Melis, and he is survived by a daughter, Giulia, and two sons, Giacomo and Giovanni.

Andrea Mosca

Dipartimento di Fisiopatologia MedicoChirurgica e dei Trapianti, Università degli Studi di Milano, Italy E-mail: andrea.mosca@unimi.it 